\title{
Caracterización clínica y genético-molecular de un paciente con enfermedad granulomatosa crónica ligada al $X$. Reporte de una nueva mutación asociada al splicing. Caso clínico
}

\author{
JUAN A. LÓPEZ Q. ${ }^{1}$, GABRIEL J. VÉLEZ T. ${ }^{1}$, MIGUEL Á. MENDIVIL P. ${ }^{2}$ \\ 1. Grupo de Inmunodeficiencias primarias, Universidad de Antioquia-Medellín, Colombia. \\ 2. Grupo de Neurociencias de Antioquia, Medellín, Colombia.
}

\begin{abstract}
Clinical, genetic and molecular characterization of the X-linked chronic granulomatous disease. A case report of a new splicing mutation

Chronic granulomatous disease (CGD) is caused by mutations in the genes that encode five of the subunits of the human NADPH oxidase. The most common form is caused by mutations in CYBB, the human gene encoding gp 91 phox. Objective: To identify the molecular defects causing CGD. Case report: A male patient with a history of acute diarrhea and recurrent perianal abscess since two months old. At 6 months, the patient presented a chronic inflammatory disease of the colon and bacterial colitis. After three years, he developed infections in the lower and perianal respiratory tract. The cDNA analysis identified abnormal mRNA expression, which was confirmed by sequencing. Specifically the exclusion of exon 2 was observed. Additionally, gDNA sequencing identified an alteration in the acceptor splice site of intron 1, including a deletion followed by insertion of three nucleotides (c.46-14_-11delTTCT insGAA). Conclusions: The first molecular study of a patient with CGD due to splicing pattern change, reported in Colombia, is presented. The definition of the mutation and its correlation with the phenotype is essential to provide appropriate genetic counseling to patients and their families.

(Key words: Chronic granulomatous disease, gp 91 phox, splicing, NADPH oxidase).

Rev Chil Pediatr 2014; 85 (2): 213-221
\end{abstract}

\section{RESUMEN}

Introducción: La Enfermedad Granulomatosa Crónica (EGC) se presenta como consecuencia de mutaciones en los genes que codifican 5 de las subunidades del sistema NADPH oxidasa humano. Su forma más común es causada por cambios en el gen CYBB que codifica gp91 phox. Objetivo: Identificar el defecto molecular que

Recibido el 31 de julio de 2013, devuelto para corregir el 14 de octubre de 2013, segunda versión 4 de noviembre de 2013, aceptado para publicación el 24 de enero de 2014.

Este trabajo cumple con los requisitos sobre consentimiento /asentimiento informado, comité de ética, financiamiento, estudios animales y sobre la ausencia de conflictos de intereses según corresponda.

Correspondencia a:

Juan Alvaro López Quintero

E-mail: jalvarolopez@gmail.com 
lleva a la presentación de la EGC. Caso clínico: Paciente de sexo masculino con antecedentes de enfermedad diarreica aguda y abscesos perianales recurrentes desde los 2 meses. A los 6 meses, presentó una inflamación crónica del colon y colitis bacteriana. A los 3 años tenía infecciones en las vías respiratorias inferiores y perianales. Estudio compatible con EGC. El análisis del ADNc identificó expresión anormal del ARNm, lo cual se confirmó al realizar la secuenciación. Específicamente se observó la ausencia del exón 2. Adicionalmente, los datos de la secuenciación del ADNg identificaron una alteración en el sitio aceptor de "splicing" del intrón 1, que incluye una deleción seguida de la inserción de 3 nucleótidos (c.46-14_-11delTTCT insGAA). Conclusiones: Se presenta el primer estudio molecular de un paciente con EGC por defecto de "splicing" reportado en Colombia. La definición de la mutación y su correlación con el fenotipo es importante para proveer una apropiada consejería genética al paciente y su familia.

(Palabras clave: Enfermedad Granulomatosa crónica, gp91 phox, splicing, NADPH oxidasa).

Rev Chil Pediatr 2014; 85 (2): 213-221

\section{Introducción}

La Enfermedad Granulomatosa Crónica (EGC) es una inmunodeficiencia primaria caracterizada por la incapacidad en la destrucción de microorganismos, debido a una deficiente producción de anión superóxido y de otras especies reactivas del oxígeno (ROS, por sus siglas en inglés) en los fagosomas de los neutrófilos, a pesar que realizan quimiotaxis, fagocitosis y degranulación normalmente'. Se presenta por una alteración en cualquiera de los componentes del sistema de la NADPH oxidasa, como resultado de mutaciones que afectan los genes que codifican para las proteínas gp91 phox, p22 phox, p47 phox, p67 phox o p40 phox $^{2,3}$. Este complejo está localizado en la membrana plasmática y de gránulos específicos de las células fagocíticas y se compone de varias proteínas localizadas en la membrana y en el citosol ${ }^{1,2}$.

Para la producción de ROS por el sistema NADPH oxidasa, es necesaria la interacción de los componentes de membrana (gp91 phox y p22 phox), con los componentes citosólicos (p47 phox, p67 phox y p40 phox) y las proteínas Rac. En estado de reposo, las proteínas de membrana y las citosólicas se encuentran separadas, pero ante un estímulo externo tal como la presencia de microorganismos o mediadores proinflamatorios, comienza el proceso de explosión respiratoria ${ }^{3,4}$.

Los pacientes con EGC presentan alteraciones en la producción de ROS lo cual los hace susceptibles a presentar infecciones graves a repetición que involucran úlceras crónicas, ganglios linfáticos que drenan y neumonía, además se pueden afectar órganos como hígado, huesos y riñones ${ }^{5}$. Los microorganismos más comúnmente aislados incluyen bacterias especialmente catalasa positiva, como Staphylococcus aureus y bacilos gram-negativos, especies de Nocardia, hongos como Aspergilius fumigatus, Candida albicans, Cándida glabrata y Pseudallescheria boydii ${ }^{6-9}$. La incidencia mundial de la EGC oscila entre 1 por cada 200 ó 250 mil nacimientos ${ }^{10}$ y en América Latina, en estudios realizados en Argentina, Chile, Costa Rica y Uruguay, se presenta una incidencia que está entre 0,72 a 1,26 casos por cada 100 mil nacimientos ${ }^{11}$.

La EGC sigue un patrón de herencia que puede estar ligado al cromosoma $\mathrm{X}$, cuando la proteína afectada es la gp91 phox o autosómico recesivo en caso que exista alguna alteración en los componentes p47 phox, p22 phox, p67 phox o p40 phox ${ }^{12-18}$. Los tipos de mutaciones que causan la EGC ligada al sexo (EGC-X), se asocian con aproximadamente el $70 \%$ de los casos $^{2}$. Dentro de las mutaciones en el gen CYBB se han reportado deleciones $(35,6 \%)$, inserciones $(7,9 \%)$ y deleciones/ inserciones $(2,8 \%)$. Así mismo se han reportado defectos en "sitios de splicing" $(17,6 \%)$, mutaciones "missense" $(21,3 \%)$, "nonsense" $(14,1 \%)$ y mutaciones en regiones promotoras $(0,7 \%)^{19}$.

El objetivo es reportar un paciente con EGC por un defecto de "splicing". En este paciente, se encontró una alteración en el sitio acep- 
tor de "splicing" del intrón 1 del gen CYBB, consistente en una deleción de 4 nucleótidos seguida de la inserción de 3 nucleótidos (c.4614_-11delTTCT insGAA).

\section{Caso clínico}

Paciente de sexo masculino, producto del primer embarazo, con controles prenatales, buena evolución y parto vaginal espontáneo. Presenta esquema de vacunación completo sin reacciones anormales. A los dos meses de edad presentó enfermedad diarreica aguda más abscesos perianales recurrentes. A los 6 meses de edad presentó inflamación crónica del colon y colitis bacteriana producida por Salmonella $\mathrm{sp}$, requirió hospitalización durante 3 semanas con tratamiento antibiótico. A los 3 años de edad consultó nuevamente porque presentaba cuadros gripales, infección en el tracto respiratorio inferior, eritema en la región perianal, síntomas dispépticos y adenopatía en la cadena cervical posterior. Un año más tarde comenzó a presentar forúnculos en la cara, dolor abdominal difuso, diarrea ocasional, hábito intestinal de 3 a 4 veces al día y absceso en la región perianal. Dentro de los antecedentes familiares, la madre relató presentar abscesos recurrentes desde los 17 años pero no recibe tratamiento médico.

\section{Reducción de Nitroblue Tetrazolium (NBT)}

Al paciente, su madre y el control sano se les tomaron muestras de sangre venosa periférica sin anticoagulante con una jeringa de $1 \mathrm{ml}$ y se depositaron 6 gotas sobre un portaobjetos precalentado para incubar a $37^{\circ} \mathrm{C}$ durante 30 min en cámara húmeda, posteriormente las láminas fueron lavadas con PBS precalentado a $37^{\circ} \mathrm{C}$ para retirar el coagulo formado, después del lavado las muestras fueron incubadas nuevamente a $37^{\circ} \mathrm{C}$ y se cubrieron completamente con $2 \mathrm{ml}$ de la solución de NBT (Sigma $\mathrm{N}-6876) 1 \mathrm{mg} / \mathrm{mL}$, previamente mezclado con forbol miristato acetato (PMA) (Sigma Chemical Co.) $1 \mathrm{mg} / \mathrm{ml} \mathrm{a} 37^{\circ} \mathrm{C}$ durante $12 \mathrm{~min}$. Las láminas fueron fijadas con metanol, teñidas con safranina al $1 \%$ y visualizadas en microscopio óptico. Se contaron 200 neutrófilos en campo de inmersión (100X), la generación de radicales de oxígeno se evidenció por medio de la reducción del colorante NBT en células activadas con PMA, con la consecuente formación de precipitados de formazán de color azul oscuro. Más del 95\% de los neutrófilos normales deben reducir el NBT.

\section{Citometría de flujo con dihidrorodamina (DHR)}

Se tomaron $4 \mathrm{ml}$ sangre venosa periférica con EDTA del paciente, su madre y el control sano. $400 \mu \mathrm{l}$ de sangre más $4 \mathrm{ml}$ de una solución de lisis (Cloruro de amonio $8,3 \mathrm{mg} / \mathrm{ml}$, bicarbonato de sodio $0,84 \mathrm{mg} / \mathrm{ml}$ y EDTA 0,5 M) se incubaron a $37^{\circ} \mathrm{C}$ durante $5 \mathrm{~min}$, posteriormente fueron centrifugados a $200 \mathrm{~g}$. El botón de células obtenido fue lavado con buffer HBSS (Hank's Buffered Salt Solution), se adicionaron $400 \mu \mathrm{L}$ de una solución de trabajo (800 $\mu \mathrm{l}$ de buffer HBSS, 3,6 $\mu 1$ de DHR 123 $29 \mathrm{mM}$ (invitrogen) y $10 \mu \mathrm{l}$ de una solución de catalasa-buffer HBSS $1 \mathrm{X}$ ) y se incubó a $37^{\circ} \mathrm{C}$ durante $5 \mathrm{~min}$. Para la estimulación de los neutrófilos se adicionaron $100 \mu \mathrm{L}$ de PMA (Sigma Chemical Co.) $1 \mathrm{mg} / \mathrm{mL}$ y se incubó a $37^{\circ} \mathrm{C}$ durante $14 \mathrm{~min}$. La activación del sistema NADPH oxidasa fue determinada por la fluorescencia generada por la DHR 123, producto de la oxidación de la DHR por el peróxido de hidrógeno. La medición fue realizada por citometría de flujo en un citómetro Becton Dickinson FACSCanto II.

\section{Separación de células mononucleares de sangre periférica (CMSP)}

Se tomaron $15 \mathrm{ml}$ de sangre venosa periférica en tubo con heparina del paciente, su madre y el control sano. La muestra fue diluida en tampón PBS (proporción 1:2), esta mezcla fue depositada en un tubo que contenía Ficoll 1077 en una proporción 1:3 con respecto a la mezcla y se centrifugó a 650 g durante 20 min a temperatura ambiente, el anillo de células mononucleares obtenido fue extraído cuidadosamente y lavado con PBS, posteriormente se centrifugó a $340 \mathrm{~g}$ durante $10 \mathrm{~min}$ a temperatura ambiente. La pureza y viabilidad de las células se determinó por conteo en cámara de Neubauer a través de tinción con violeta de genciana y azul de tripano respectivamente. 
Las células aisladas tenían porcentajes de viabilidad y pureza superiores al $95 \%$.

\section{Extracción de ARN, síntesis de ADNc y PCR}

El ARN fue extraído a partir de CMSP por el método de TRIzol (Invitrogen). El ADN copia (ADNc) fue obtenido a partir del ARN total por transcripción reversa utilizando el sistema ThermoScript RT-PCR System (Invitrogen) de acuerdo a las especificaciones del fabricante. Para el estudio del ADNc de gp91 phox se utilizó una estrategia en la que se amplificaron 3 regiones superpuestas con el fin de abarcar todo el exoma, para ello se utilizaron tres pares de cebadores (tabla 1) que amplificaron las regiones comprendidas entre los exones 1-5, 3-9 y $7-13$.

Las condiciones de la PCR fueron: $2 \mathrm{~min}$ a $95^{\circ} \mathrm{C}, 30$ ciclos que incluían $95^{\circ} \mathrm{C}$ por $15 \mathrm{~s}$, $63^{\circ} \mathrm{C}$ por $30 \mathrm{~s}$ (regiones $1-5$ y $7-13$ ) o $42^{\circ} \mathrm{C}$ por $30 \mathrm{~s}$ (región $3-9$ ) y $72^{\circ} \mathrm{C}$ por $45 \mathrm{~s}$, además de una extensión final a $72^{\circ} \mathrm{C}$ por $7 \mathrm{~min}$. Los productos obtenidos fueron analizados por electroforesis en gel de agarosa al 1,5\%, previamente mezclado con SYBR safe (invitrogen). Los fragmentos fueron de $450 \mathrm{pb}$ para la región $1-5,700 \mathrm{pb}$ para la región 3-9 y de 900 pb para la región 7-13.

\section{Extracción de ADN genómico y PCR}

El ADN genómico (ADNg) fue extraído a partir de CMSP por el método de TRIzol (invitrogen) de acuerdo a las especificaciones del fabricante. Utilizando Cebadores o primers específicos (tabla 1), se amplificó el exón 2 del gen CYBB incluyendo los bordes de los intrones 1 y 2 . Las condiciones de la PCR fueron 2 min a $95^{\circ} \mathrm{C}, 30$ ciclos que incluían $95^{\circ} \mathrm{C}$ por $15 \mathrm{~s}, 63^{\circ} \mathrm{C}$ por $30 \mathrm{~s} \mathrm{y} 72^{\circ} \mathrm{C}$ por $45 \mathrm{~s}$, además de una extensión final a $72^{\circ} \mathrm{C}$ por $7 \mathrm{~min}$. Los productos obtenidos fueron analizados en gel de agarosa al 1,5\% teñido con SYBR safe (invitrogen). El fragmento obtenido fue de aproximadamente $230 \mathrm{pb}$.

\section{Polimorfismos conformacionales de cadena sencilla (SSCP)}

Se estudió el polimorfismo conformacional de los fragmentos generados por PCR del ADN genómico. Los productos amplificados más el buffer de carga $(0,05 \%$ de azul de bromofenol, $0,05 \%$ cyanol xylene, $95 \%$ formamida y $20 \mathrm{mM}$ EDTA) fueron desnaturalizados a $95^{\circ} \mathrm{C}$ por 5 min y puestos inmediatamente en hielo. Las muestras fueron corridas una electroforesis no denaturante (utilizando un gel de acrilamida al $12 \%$ disuelto en tampón TBE $10 \%$ de glicerol) utilizando 90 voltios a $10^{\circ} \mathrm{C}$ durante $10 \mathrm{~h}$. El gel con los productos de AND fue fijado con ácido acético al 10\% durante 30 min y teñido empleando una solución de nitrato de plata $0,1 \%$ y formaldehido 0,14\% durante 30 min. El revelado se llevó a cabo utilizando una solución de carbonato de sodio $3 \%$, formaldehido $0,15 \%$ y tiosulfato de sodio $0,02 \%$. El perfil de migración de las bandas del paciente y de la madre fue comparado con el control sano.

Tabla 1. Cebadores utilizados para al análisis del CDNA y el gDNA del gen CYBB

\begin{tabular}{|c|c|c|c|}
\hline Región & & Secuencia del primer & $\begin{array}{c}\text { Tamaño del pro- } \\
\text { ducto }\end{array}$ \\
\hline \multirow[t]{2}{*}{ Exones 1-5 } & Gp91-phox F & $5^{\prime}$ gct cta gag cat gag ggg ctc tcc att ttt gtc a $3^{\prime}$ & $450 \mathrm{pb}$ \\
\hline & Gp91-phox R & $5^{\prime}$ cgg gat ccc gat ttc aga gag tgc tac tga ata a $3^{\prime}$ & \\
\hline \multirow[t]{2}{*}{ Exones 3-9 } & Gp91-phox F & $5^{\prime}$ gcc tgc ctg aat ttc aac $3^{\prime}$ & $700 \mathrm{pb}$ \\
\hline & Gp91-phox R & $5^{\prime}$ tca tct gta gct cga tg $3^{\prime}$ & \\
\hline \multirow[t]{2}{*}{ Exones 7-13 } & Gp91-phox F & $5^{\prime}$ gga atg ccc aat ccc tca g 3' & $900 \mathrm{pb}$ \\
\hline & Gp91-phox R & $5^{\prime}$ ggg cca gac tca gag ttg g $3^{\prime}$ & \\
\hline \multirow[t]{2}{*}{ Exón 2} & Gp91-phox 2LA & $5^{\prime}$ gac ttg gga agt cct gac cc $3^{\prime}$ & $230 \mathrm{pb}$ \\
\hline & Gp91-phox 2RA & $5^{\prime}$ cca gcc aat aat gca tgg ga $3^{\prime}$ & \\
\hline
\end{tabular}




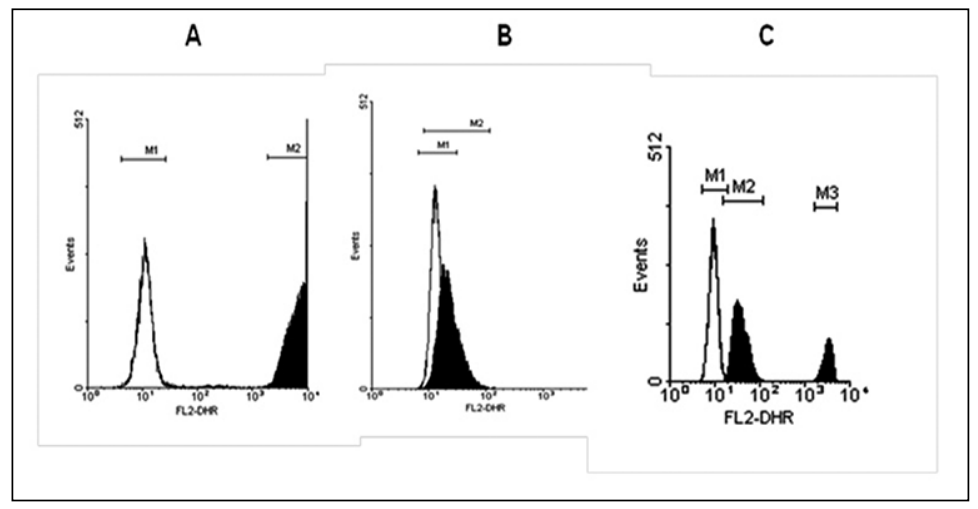

Figura 1. Citometría de flujo con dihidrorodamina (DHR). Los histogramas corresponden a la población de neutrófilos en reposo (barra sin relleno) y estimulados con PMA (barra negra). La estimulación produce un incremento en la intensidad media de la fluorescencia en la población de neutrófilos que produce ROS. A: Intensidad media de la fluorescencia mayor en individuo control. B: Actividad oxidativa deficiente en el paciente con EGC. C: La madre presenta dos niveles distintos de actividad oxidativa, correspondientes a dos poblaciones de PMNs, típico en las portadoras de la enfermedad.

\section{Secuenciación}

Los productos obtenidos por PCR tanto de $\mathrm{ADNc}$ como $\mathrm{ADNg}$ fueron secuenciados con técnicas estándares (Macrogen Inc. Seul, Korea). Las secuencias de pacientes y controles fueron comparadas con las secuencias normales a partir de los datos de GeneBank (Número de acceso NM_000397).

El presente estudio contó con la aprobación del Comité de Ética de la Facultad de Medicina de la Universidad de Antioquia. MedellínColombia. La identidad de los sujetos de este estudio se mantiene en confidencialidad.

\section{Resultados}

\section{Diagnóstico bioquímico de la enfermedad}

Las pruebas de NBT y DHR fueron empleadas para hacer el diagnóstico bioquímico de la EGC. Los PMN del paciente no mostraron reducción del colorante NBT después de la estimulación con PMA, mientras que en la madre se observó un patrón de mosaico en el que un grupo de células reduce el NBT y forman precipitados de formazán y otras no lo hacen, lo cual es compatible con estado de portadora de la enfermedad (datos no mostrados). Así mismo, la explosión respiratoria cuantificada por citometría de flujo, a través de DHR, reveló una ausencia de esta función en el paciente después de la estimulación, mientras que en la madre se observan dos poblaciones celulares con diferentes niveles de explosión respiratoria (figura 1), confirmando así el estado de portadora en la madre y por ende una herencia ligada al cromosoma X.

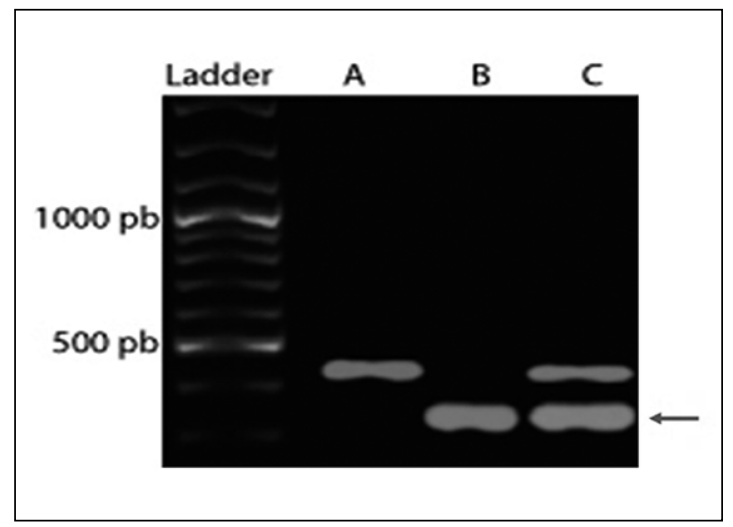

Figura 2. Electroforesis en gel de agarosa para los productos de ADNc obtenidos por PCR para los exones 1-5. A: Individuo control, correspondiente a un tamaño aproximado de 450pb. B: Paciente, se presenta una banda de menor tamaño (señalada con una flecha). C: Madre, se aprecian dos bandas de diferente tamaño correspondientes a la expresión del alelo defectuoso (señalado con una flecha) y del normal portadora.

\section{Análisis de la expresión de ARNm}

El análisis del ADNc de gp91 phox de los productos obtenidos por PCR de los exones 1-5, 3-9 y 7-13 reveló un patrón de migración anormal en la región 1-5 en el paciente. Se observó una banda de menor tamaño con respecto al control, mientras que en la madre se evidenció la presencia de dos bandas de diferente tamaño, una similar a la del paciente y otra con el mismo perfil electroforético del control, es decir, la expresión de un alelo normal y uno mutado que da la característica de portadora (figura 2). Para confirmar el defecto específico en el ADNc, se realizó la secuenciación de la 

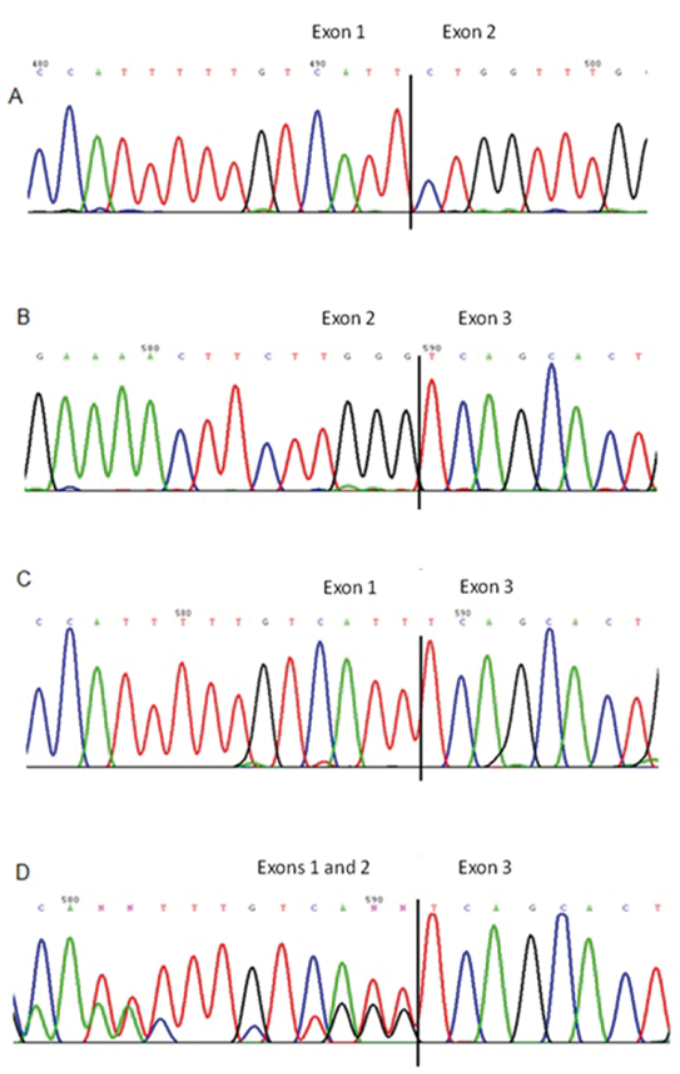

Figura 3. Secuenciación del ADNc de control, paciente y madre. A y B: Secuencia de la unión de los exones 1-2 y 2-3 del individuo control. C: Secuencia del paciente que muestra la región 3' del Exón 1 seguida de la región 5' del Exón 3 como consecuencia de la deleción del Exón 2. D: Secuencia de la madre portadora con la presencia de una doble secuencia. La barra representa el límite entre un exón y otro.

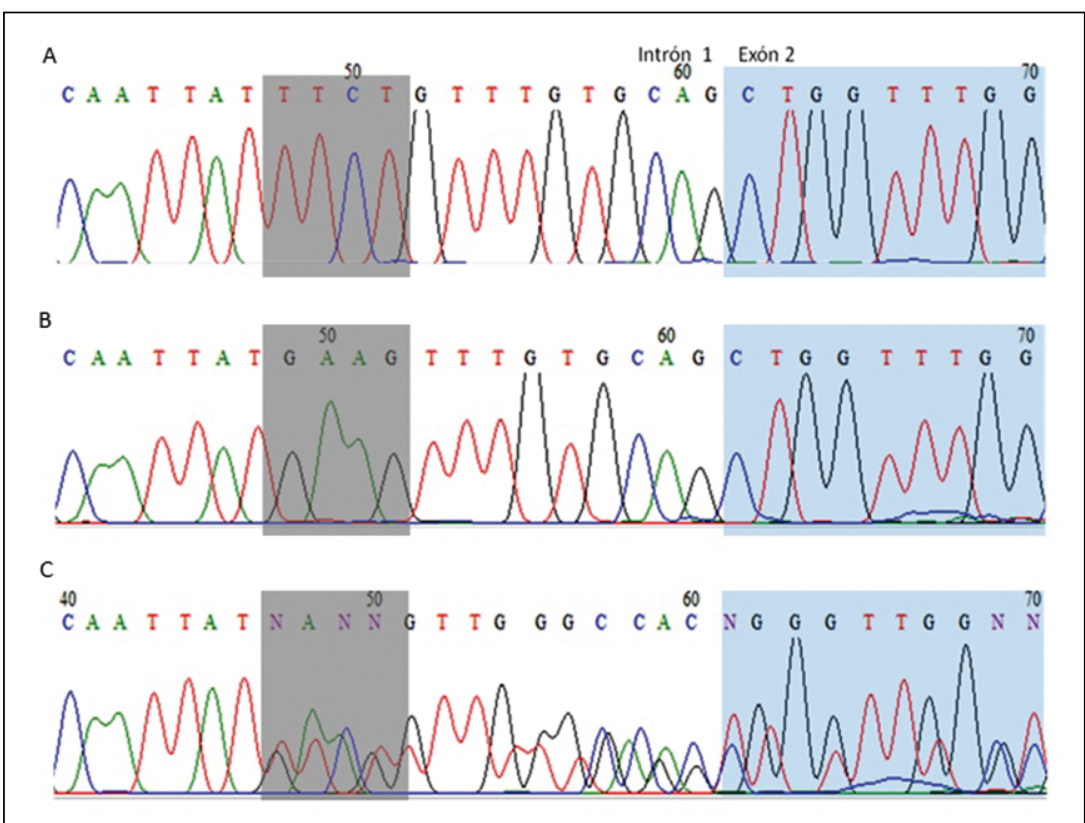

Figura 4. Secuenciación del ADN genómico. A: secuencia del individuo control. B: secuencia del paciente que muestra una alteración en el sitio aceptor de "splicing" del intrón 1 (zona sombreada en gris), que incluye una deleción de 4 nucleótidos seguida de la inserción de 3 nucleótidos (c.46-14_-11delTTCT insGAA). C: secuencia de la madre que muestra la secuencia normal y la mutada. La zona sombreada en azul corresponde al inicio del exón 2. 
región comprendida entre los exones 1-5. Los resultados mostraron la ausencia total del exón 2 en el paciente, mientras que en la madre se observó una secuencia normal y otra mutada con la deleción del exón 2 (figura 3).

\section{Análisis del ADN genómico}

Teniendo en cuenta la ausencia del exón 2, se procedió a analizar el $\mathrm{ADNg}$ con el fin de determinar el sitio exacto de la mutación. En primera instancia, ADN del paciente, de la madre y del control fue utilizado para amplificar el exón 2 incluyendo los bordes de los intrones 1 y 3. El análisis por SSCP evidenció un patrón de migración alterado tanto en el paciente, como en la madre, con respecto al control (datos no mostrados). La secuenciación de esta región identificó una alteración en el sitio aceptor de "splicing" del intrón 1, consistente en una deleción de 4 nucleótidos seguida de la inserción de 3 nucleótidos (c.4614_-11delTTCT insGAA) (figura 4).

\section{Discusión}

La EGC ligada al cromosoma X es una enfermedad que se presenta cuando hay alteraciones en el gen CYBB que codifica para la proteína gp91 phox. Las múltiples infecciones que presentó el paciente de manera recurrente llevó a la sospecha de algún desorden en su sistema inmune, el tipo de manifestaciones tales como abscesos recurrentes, inflamación del tracto gastrointestinal, infección en las vías respiratorias inferiores y adenopatías coinciden con las presentaciones clínicas asociadas a la $\mathrm{EGC}^{20}$.

El uso de la prueba de NBT y la citometría de flujo con DHR permiten establecer el diagnóstico bioquímico e igualmente contribuyen a identificar el patrón de herencia de la enfermedad. Los resultados negativos de estas pruebas en el paciente demostraron la incapacidad de las células fagocíticas para producir ROS $(0 \%)$ (figura 1). En la madre la presentación en mosaico en el NBT y las dos poblaciones celulares observadas a través de citometría de flujo con la DHR, permitió demostrar su estado de portadora el cual se puede relacionar con la presentación de abscesos recurrentes desde los 17 años. En este reporte se pudo correlacionar el defecto bioquímico con las alteraciones moleculares que llevaron a una falla en la explosión respiratoria.

La electroforesis de los Exones 1-5 del ADNc del paciente mostró una banda de menor tamaño con respecto al control (figura 2). De especial importancia fue el resultado de la madre pues en ella se logró evidenciar en el fragmento 1-5 una banda de menor tamaño igual a la del paciente, correspondiente a un alelo mutado y una banda de tamaño igual a la del control que corresponde al alelo normal. Este hallazgo se correlacionó con el diagnóstico bioquímico de la enfermedad, debido a que en la madre se observó un patrón de portadora de la EGC. Así, los resultados obtenidos a través del estudio de la secuencia ADNc, (figura 3) permitieron observar la deleción del exón 2 , resultados que llevaron a la sospecha de una posible mutación que estuviera afectando el procesamiento del ARNm.

La secuenciación del ADNg identificó una alteración en el sitio aceptor de splicing del intrón 1 , que incluye una deleción de 4 nucleótidos seguida de la inserción de 3 nucleótidos (c.46-14_-11delTTCT insGAA) (figura 4), este defecto fue previamente reportado por nuestro grupo en la tercera base de datos de mutaciones en individuos con $\mathrm{EGC}^{19}$. Esta mutación probablemente originó un defecto en la maquinaria del "spliceosoma" para llevar a cabo el procesamiento del ARN primario, generándose un corte en el 5' del intrón 1 y haciendo el empalme con el sitio 3' del intrón 2 , ocasionando la deleción total del exón 2 . Esta deleción podría traer como consecuencia directa la traducción incompleta de las regiones de unión transmembrana de la proteína gp91 phox (NCBI Reference Sequence: NM_007052.4; gráfico disponible en: http:// www.ncbi.nlm.nih.gov/nuccore/148536872?r eport=graph).

Otros estudios han descrito mutaciones en sitios de "splicing" en el gen CYBB cuyas consecuencias interfieren en el procesamiento del ARNm, en algunos casos estos defectos llevan a un fenotipo en el que no se expresa la proteína o en otros casos hay expresión de una proteína con alteraciones funcionales ${ }^{19,21-24}$. En un 
estudio realizado por Roesler J et al, en 1999, se describen cuatro pacientes con mutaciones en sitios de splicing, en uno de ellos se presenta la deleción total del exón 2 (ex2GGgtaagex2GGgtaaa), si bien la mutación difiere de la reportada en nuestro estudio, el fenotipo es similar ya que la producción de ROS es nula ${ }^{25}$. Así mismo, se ha reportado que las mutaciones en sitios de splicing son frecuentes en pacientes con EGC ligada al $\mathrm{X}^{25}$. Si bien las mutaciones que implican defectos en el corte y empalme del ADNc son comunes en el gen CYBB este estudio corresponde al primer reporte de un paciente colombiano con una mutación en el sitio aceptor de splicing del intrón 1 en el gen CYBB que conlleva a la presentación de la EGC.

\section{Conclusiones}

A pesar de que se han realizado extensas investigaciones acerca del sistema NADPH oxidasa y de los mecanismos, tanto moleculares como genéticos acerca de la EGC, actualmente quedan muchos vacíos en cuanto al conocimiento de esta inmunodeficiencia, lo cual deriva en la dificultad para el tratamiento terapéutico de los pacientes, ya que muchos de los mecanismos de señalización e interacción entre los componentes de este complejo enzimático aún son inciertos. Así mismo, aunque la incidencia de esta enfermedad es relativamente baja, se debe profundizar en trabajos que contribuyan a dilucidar cada uno de los mecanismos que intervienen en el proceso de la explosión respiratoria, de esta forma las alternativas para el tratamiento serán mucho más eficaces y la calidad de vida de los pacientes aumentará notablemente. Es por esto que la definición de la mutación y su correlación con el fenotipo es importante para proveer una apropiada consejería genética y pronóstico clínico al paciente y su familia.

\section{Referencias}

1.- El-Benna J, Dang PM, Gougerot-Pocidalo MA, Elbim $C$ : Phagocyte NADPH oxidase: a multicomponent enzyme essential for host defenses. Arch Immunol Ther Exp (Warsz), 2005; 53 (3): 199-206.
2.- Heyworth PG, Cross AR, Curnutte JT: Chronic granulomatous disease. Curr Opin Immunol 2003; 15 (5): 578-84.

3.- Jurkowska M, Bernatowska E, Bal J: Genetic and biochemical background of chronic granulomatous disease. Arch Immunol Ther Exp (Warsz) 2004; 52 (2): 113-20.

4.- Vignais $P$ : The superoxide-generating NADPH oxidase: structural aspects and activation mechanism. Cell Mol Life Sci 2002; 59 (9): 1428-59.

5.- Loffredo L: Chronic Granulomatous disease. Intern Emerg Med 2011; 6 Suppl 1: 125-8.

6.- Johnston RB Jr: Clinical aspects of chronic granulomatous disease. Curr Opin Hematol 2001; 8 (1): 17-22.

7.- Stasia MJ, Li XJ: Genetics and immunopathology of chronic granulomatous disease. Semin Immunopathol 2008; 30 (3): 209-35.

8.- Blumental S, Mouy R, Mahlaoui N, et al: Invasive mold infections in chronic granulomatous disease: a 25-year retrospective survey. Clin Infect Dis 2011; 53 (12): 15969.

9.- $\quad$ Song E, Jaishankar GB, Saleh H, Jithpratuck W, Sahni $R$, Krishnaswamy $G$ : Chronic granulomatous disease: a review of the infectious and inflammatory complications. Clin Mol Allergy 2011; 9 (10).

10.- Cale CM, Morton L, Goldblatt D: Cutaneous and other lupus-like symptoms in carriers of X-linked chronic granulomatous disease: incidence and autoimmune serology. Clin Exp Immunol 2007; 148: 79-84.

11.- Leiva LE, Zelazco M, Oleastro $M$, et al: Primary immunodeficiency diseases in Latin America: the second report of the LAGID registry. J Clin Immunol 2007; 27 (1): 101-8.

12.- Babior BM: NADPH oxidase. Curr Opin Immunol: 2004; 16 (1): 42-7.

13.- Arai T, Oh-ishi T, Yamamoto H, et al: Copy Number Variations Due to Large Genomic Deletion in X-Linked Chronic Granulomatous Disease. PLoS One 2012; 7 (2): e27782.

14.- Stasia MJ, Bordigoni P, Floret D, et al: Characterization of six novel mutations in the CYBB gene leading to different sub-types of X-linked chronic granulomatous disease. Hum Genet 2005; 116 (1-2): 72-82.

15.- Segal BH, Leto TL, Gallin JI, Malech HL, Holland SM: Genetic, biochemical, and clinical features of chronic granulomatous disease. Medicine (Baltimore) 2000; 79 (3): 170-200.

16.- Winkelstein JA, Marino MC, Johnston $R B J r$, et al: Chronic granulomatous disease. Report on a national registry of 368 patients. Medicine (Baltimore) 2000; 79 (3): 155-69. 
17.- Roos D, de Boer M, Kuribayashi F, et al: Mutations in the X-linked and autosomal recessive forms of chronic granulomatous disease. Blood 1996; 87 (5): 1663-81.

18.- Rae J, Noack D, Heyworth PG, Ellis BA, Curnutte JT, Cross AR: Molecular analysis of 9 new families with chronic granulomatous disease caused by mutations in CYBA, the gene encoding p22 (phox). Blood 2000; 96 (3): 1106-12.

19.- Roos D, Kuhns DB, Maddalena A, et al: Hematologically important mutations: X-linked chronic granulomatous disease (third update). Blood Cells Mol Dis 2010; 45 (3): 246-65.

20.- Seger RA: Modern management of chronic granulomatous disease. Br J Haematol 2008; 140 (3): 255-66.

21.- Lewis EM, Singla M, Sergeant S, Koty PP, McPhail LC: $\mathrm{X}$-linked chronic granulomatous disease secondary to skewed $\mathrm{X}$ chromosome inactivation in a female with a novel CYBB mutation and late presentation. Clin
Immunol 2008; 129 (2): 372-80.

22.- Brunner J, Dockter G, Rösen-Wolff A, Roesler J: Xlinked chronic granulomatous disease (CGD) caused by an intra-exonic splice mutation (CYBB exon 3, c. $262 \mathrm{G} \rightarrow \mathrm{A}$ ) is mimicking juvenile sarcoidosis. Clin Exp Rheumatol 2007; (2): 336-8.

23.- Rump A, Rösen-Wolff A, Gahr $M$, et al: A splicesupporting intronic mutation in the last bp position of a cryptic exon within intron 6 of the CYBB gene induces its incorporation into the mRNA causing chronic granulomatous disease (CGD). Gene 2006; 371 (2): 174-81.

24.- de Boer M, Bolscher BG, Dinauer MC, et al: Splice site mutations are a common cause of $\mathrm{X}$-linked chronic granulomatous disease. Blood 1992; 80 (6): 1553-8.

25.- Roesler J, Heyden S, Burdelski M, et al: Uncommon missense and splice mutations and resulting phenotypes in German patients with X-linked chronic granulomatous disease. Exp Hematol 1999; 27 (3): 505-11. 